$$
\text { Special Article }
$$

\title{
A COMPARISON OF DIETARY TRENDS AMONG RACIAL AND SOCIOECONOMIC GROUPS IN THE UNITED STATES
}

\author{
Barry M. Popkin, Ph.D., Anna Maria Siega-Riz, Ph.D., and Pamela S. Haines, Ph.D.
}

\begin{abstract}
Background There may be dietary differences among racial and socioeconomic groups in the United States.

Methods Using data from a representative sample of adults, we compared dietary trends among blacks and whites of varying socioeconomic status. We developed comparable measures of diet and of the consumption of macronutrients and food groups for 6061 participants in the 1965 Nationwide Food Consumption Surveys, 16,425 in the 1977-1978 Nationwide Food Consumption Surveys, and 9920 in the 1989-1991 Continuing Survey of Food Intake by Individuals (all conducted by the U.S. Department of Agriculture). The primary outcome was the score (range, 0 to 16) on the Diet Quality Index, a composite of eight food-and-nutrient-based recommendations from the National Academy of Sciences. A score of 4 or less was considered to indicate a relatively more healthful diet, and a value of 10 or more a relatively less healthful diet.
\end{abstract}

Results Overall dietary quality improved in all groups, from a mean Diet Quality Index score of 7.4 in 1965 to 6.4 in 1989-1991. In 1965, blacks of low socioeconomic status and, to a lesser extent, whites of low socioeconomic status had better diets than whites of high socioeconomic status. By the 19891991 survey, the differences among racial and socioeconomic groups had narrowed. In 1965, 9.3 percent of whites of low socioeconomic status, 16.4 percent of blacks of low socioeconomic status, and 4.7 percent of whites of high socioeconomic status had mean scores of 4 or less. In the 1989-1991 survey, the respective percentages were 19.9, 23.5, and 20.0. Fat consumption decreased in all groups. The consumption of fruits and vegetables varied little over time, except for an increase among blacks of medium and high socioeconomic status. The consumption of grains and legumes increased over time among whites of medium and high socioeconomic status and declined among blacks of low socioeconomic status.

Conclusions In 1965, there were large differences among groups in dietary quality, with whites of high socioeconomic status eating the least healthful diet, as measured by the index, and blacks of low socioeconomic status the most healthful. By the 1989-1991 survey, the diets of all groups had improved and were relatively similar. (N Engl J Med 1996;335:716-20.) (C)1996, Massachusetts Medical Society.
1

LTHOUGH research on patterns of obesity and serum cholesterol concentrations suggests possible differences in diet according to race and socioeconomic status, few nationally representative studies in the United States describe dietary differences related to race or income. ${ }^{1-4}$ In general, blacks consume less fat and energy than whites, but more cholesterol. ${ }^{5} \mathrm{~A}$ crosssectional analysis found that blacks also consume fewer fruits and vegetables than whites. 6 Dietary trends over time have not been systematically explored, and the analyses have been limited by the use of aggregate food-group categories that do not reflect important patterns in the intake of fat and fiber. The use of household data, rather than data on individual diets, has also limited previous work.7-10

We used data on individual diets from a representative sample of the United States population to compare dietary trends in racial and socioeconomic groups between 1965 and 1989-1991.

\section{METHODS}

\section{Survey Design and Sample}

From over 60,000 participants in three U.S. Department of Agriculture (USDA) surveys, we selected the nonpregnant adults (18 years of age or older) who were either white or black and for whom dietary data were available as our final sample. Of these 32,406 subjects, 6061 were respondents to the 1965 Nationwide Food Consumption Surveys, 16,425 to the 1977-1978 Nationwide Food Consumption Surveys, and 9920 to the 1989-1991 Continuing Survey of Food Intake by Individuals. These USDA surveys are administered to stratified probability samples of households of the noninstitutionalized population in the 48 conterminous states. The 1977-1978 and 1989-1991 surveys were both conducted in four waves (winter, spring, summer, and fall), each of which surveyed a different sample. ${ }^{11-13}$ The 1965 survey gathered data on individual diets in a single sample in the spring. ${ }^{14}$ These surveys were multistage, stratified samples of the U.S. population in defined geographic areas. For each survey, response rates differed among the surveyed subgroups. Thus, weights, derived from the response rate for each subgroup, could be used to permit inferences applicable to the total noninstitutionalized U.S. population. ${ }^{11,12,14}$

From the Department of Nutrition, University of North Carolina, Chapel Hill. Address reprint requests to Dr. Popkin at the Carolina Population Center, CB 8120 University Square, University of North Carolina, Chapel Hill, NC 27516-3997. 
Categories of socioeconomic status were based on education and income. Respondents with over 12 completed years of education and an income that was more than 350 percent of poverty level were categorized as having high socioeconomic status; respondents with less than a high-school education and an income less than 185 percent of poverty level were categorized as having low socioeconomic status. Estimates of variance in the study are frequently larger for blacks because of their smaller number in each of the three surveys. Of note is the disproportionately small number of blacks of high socioeconomic status.

\section{Dietary Data}

In each survey, interviewers asked respondents, in the respondents' homes, to recall their diet over a one-day period (a one-day dietary recall). Information was collected on everything the respondents ate inside or outside the home. The 1977-1978 and 1989-1991 surveys also included two self-administered one-day food records. To avoid biasing the results because of different methods of data collection, we used only the information from the interviewer-administered record of dietary intake in each survey.

The 1994 USDA Nutrient Database was used to calculate the nutrient value of the food intake. A linking program was used to assign the same food code to comparable items in each period. Values from the 1994 Nutrient Database were then applied to the three data sets to provide consistent estimates of nutrient composition over time. The use of a nutrient data base developed in the 1990s to assign macronutrient values to food consumed in earlier periods should not artificially create significant differences in measurements of food energy and fat content. ${ }^{15,16}$

\section{Food Grouping}

In order to examine changes in the quantity of foods consumed over time, we developed dietary measures, including measures of macronutrients and of food groups, that could be applied to the data from all three surveys. The food-grouping system disaggregates the major USDA food groups into 56 more distinct nutrient-based groups, according to fat and dietary-fiber composition; these groups included all the foods that respondents reported eating. ${ }^{8,10}$ (A copy of the food-grouping system is available from the authors.)

\section{Diet Quality Index}

The primary measure we selected to illustrate the observed trends was the Diet Quality Index, a composite of eight recommendations regarding the consumption of foods and nutrients from the National Academy of Sciences (Table 1). ${ }^{17}$ This index reflects the risk gradient associated with diet for major diet-related chronic diseases. Respondents who met a given dietary goal received a score of 0 ; those whose consumption fell within approximately 30 percent of the goal were given a score of 1 ; and those whose consumption differed by more than 30 percent from the goal were given a score of 2 . The scores for all eight dietary goals were totaled, so that the index ranged from 0 to 16 (the lower the score, the better the diet). Details of the index's rationale, construction, and validity appear elsewhere.18,19 For the purposes of our analysis, a Diet Quality Index score of 4 or less was considered to represent a relatively more healthful diet, and a value of 10 or more a relatively less healthful diet; respondents with a Diet Quality Index score of 4 or less by definition met at least four of the eight dietary recommendations. ${ }^{17}$

Descriptive statistics on individual dietary components and the overall distribution of dietary outcomes among the respondents to each survey were generated according to race and socioeconomic status.

\section{RESULTS}

Overall, dietary quality improved between 1965 and 1989-1991. The mean ( \pm SE) Diet Quality In- dex score changed from $7.4 \pm 0.02$ to $6.4 \pm 0.01$. This improvement was seen in all racial and socioeconomic groups (Table 2). Differences in the mean Diet Quality Index score according to race and socioeconomic status have narrowed. Within the groups of low and medium socioeconomic status, the proportion of blacks with Diet Quality Index scores of 4 or less exceeded that of whites in each period. In 1965 and 1977-1978, the proportion of people with a Diet Quality Index score of 4 or less was lower in the groups of high socioeconomic status than in the groups of lower status. Notably, the upward shift in the percentage of people with a score of 4 or less was greater among whites than blacks for lowand high-socioeconomic-status groups.

By 1989-1991, whites of high socioeconomic status had the largest increase in the percentage of people with Diet Quality Index scores of 4 or less. In $1965,9.3$ percent of whites of low socioeconomic status, 16.4 percent of blacks of low socioeconomic status, and 4.7 percent of whites of high socioeconomic status had mean Diet Quality Index scores of 4 or less; in 1989-1991, the respective percentages were $19.9,23.5$, and 20.0 . In $1965,10.7$ percent of whites of low socioeconomic status, 6.1 percent of blacks of low socioeconomic status, and 16.7 percent of whites of high socioeconomic status had mean Diet Quality Index scores of 10 or more. In

Table 1. The Diet Quality Index.

\begin{tabular}{|c|c|c|}
\hline RECOMMENDATION* & Scoret & INTAKE \\
\hline $\begin{array}{l}\text { Reduce total fat intake to } 30 \% \text { or less } \\
\text { of total energy }\end{array}$ & $\begin{array}{l}0 \\
1 \\
2\end{array}$ & $\begin{array}{c}\quad \leqslant 30 \% \\
>30-40 \% \\
>40 \%\end{array}$ \\
\hline $\begin{array}{l}\text { Reduce saturated-fatty-acid intake to } \\
\text { less than } 10 \% \text { of energy }\end{array}$ & $\begin{array}{l}0 \\
1 \\
2\end{array}$ & $\begin{array}{l}<10 \% \\
10-13 \% \\
>13 \%\end{array}$ \\
\hline $\begin{array}{l}\text { Reduce cholesterol intake to less than } \\
300 \mathrm{mg} \text { daily }\end{array}$ & $\begin{array}{l}0 \\
1 \\
2\end{array}$ & $\begin{array}{c}<300 \mathrm{mg} \\
300-400 \mathrm{mg} \\
>400 \mathrm{mg}\end{array}$ \\
\hline $\begin{array}{l}\text { Eat } 5 \text { or more servings daily of vege- } \\
\text { tables and fruits }\end{array}$ & $\begin{array}{l}0 \\
1 \\
2\end{array}$ & $\begin{array}{l}\geqslant 5 \text { servings } \\
3-4 \text { servings } \\
0-2 \text { servings }\end{array}$ \\
\hline $\begin{array}{l}\text { Increase intake of starches and other } \\
\text { complex carbohydrates by eating } \\
6 \text { or more servings daily of breads, } \\
\text { cereals, and legumes }\end{array}$ & $\begin{array}{l}0 \\
1 \\
2\end{array}$ & $\begin{array}{l}\geqslant 6 \text { servings } \\
4-5 \text { servings } \\
0-3 \text { servings }\end{array}$ \\
\hline $\begin{array}{l}\text { Maintain protein intake at moderate } \\
\text { levels (levels lower than twice the } \\
\text { RDA) }\end{array}$ & $\begin{array}{l}0 \\
1 \\
2\end{array}$ & $\begin{array}{c}<100 \% \text { RDA } \\
100-150 \% \text { RDA } \\
>150 \% \text { RDA }\end{array}$ \\
\hline $\begin{array}{l}\text { Limit total daily intake of sodium to } \\
2400 \mathrm{mg} \text { or less }\end{array}$ & $\begin{array}{l}0 \\
1 \\
2\end{array}$ & $\begin{array}{c}\leqslant 2400 \mathrm{mg} \text { sodium } \\
>2400-3400 \mathrm{mg} \text { sodium } \\
>3400 \mathrm{mg} \text { sodium }\end{array}$ \\
\hline $\begin{array}{l}\text { Maintain adequate calcium intake } \\
\text { (approximately the RDA) }\end{array}$ & $\begin{array}{l}0 \\
1 \\
2\end{array}$ & $\begin{array}{l}\geqslant 100 \% \text { RDA } \\
67-99 \% \text { RDA } \\
<67 \% \text { RDA }\end{array}$ \\
\hline
\end{tabular}

*RDA denotes Recommended Daily Allowance.

†Scores for the eight recommendations are totaled to generate a Diet Quality Index score for a respondent (range, 0 to 16). 
Table 2. Mean Diet Quality Index Scores and Distribution of Individual Scores of $\leqslant 4$ or $\geqslant 10$, According to Socioeconomic Status and Race for Each Survey.*

\begin{tabular}{|c|c|c|c|c|c|c|c|c|c|}
\hline \multirow[t]{3}{*}{ RACE AND Variable } & \multicolumn{9}{|c|}{ Socioeconomic Status } \\
\hline & \multicolumn{3}{|c|}{ LOW } & \multicolumn{3}{|c|}{ MEDIUM } & \multicolumn{3}{|c|}{$\mathrm{HIGH}$} \\
\hline & 1965 & $1977-1978$ & $1989-1991$ & 1965 & 1977-1978 & $1989-1991$ & 1965 & 1977-1978 & $1989-1991$ \\
\hline \multicolumn{10}{|l|}{ Whites } \\
\hline No. of respondents & 2146 & 3144 & 3195 & 2845 & 8619 & 3994 & 381 & 2716 & 1415 \\
\hline Mean $( \pm S E)$ score & $7.2 \pm 0.03$ & $6.8 \pm 0.03$ & $6.3 \pm 0.03$ & $7.7 \pm 0.03$ & $7.1 \pm 0.02$ & $6.6 \pm 0.02$ & $7.8 \pm 0.08$ & $7.3 \pm 0.03$ & $6.4 \pm 0.05$ \\
\hline Score $\leqslant 4$ ( $\%$ of respondents $)$ & 9.3 & 12.9 & 19.9 & 5.6 & 9.4 & 17.9 & 4.7 & 8.5 & 20.0 \\
\hline Score $\geqslant 10$ ( $\%$ of respondents $)$ & 10.7 & 6.7 & 4.4 & 15.1 & 9.5 & 6.8 & 16.7 & 12.4 & 6.6 \\
\hline \multicolumn{10}{|l|}{ Blacks } \\
\hline No. of respondents & 504 & 1065 & 948 & 179 & 763 & 328 & $6 \dagger$ & 118 & 40 \\
\hline Mean $( \pm S E)$ score & $6.6 \pm 0.08$ & $6.5 \pm 0.05$ & $6.2 \pm 0.05$ & $7.2 \pm 0.14$ & $6.7 \pm 0.06$ & $6.4 \pm 0.09$ & - & $7.3 \pm 0.17$ & $6.0 \pm 0.28$ \\
\hline Score $\leqslant 4$ ( $\%$ of respondents $)$ & 16.4 & 18.2 & 23.5 & 10.0 & 14.4 & 22.8 & - & 6.7 & 2.7 \\
\hline Score $\geqslant 10$ (\% of respondents $)$ & 6.1 & 5.0 & 4.1 & 12.2 & 4.4 & 5.1 & - & 14.4 & 0 \\
\hline
\end{tabular}

* The lower the Diet Quality Index score, the better the diet.

†The sample was too small to present meaningful results.

Table 3. Intake of Dietary Components According to Socioeconomic Status and Race for Each Survey.*

Race ANd Component

Socioeconomic Status

\begin{tabular}{|c|c|c|c|c|c|c|c|}
\hline \multicolumn{3}{|c|}{ LOW } & \multicolumn{3}{|c|}{ MEDIUM } & \multicolumn{2}{|c|}{$\mathrm{HIGH}$} \\
\hline 1965 & $1977-1978$ & $1989-1991$ & 1965 & $1977-1978$ & $1989-1991$ & 1965 & $1989-1991$ \\
\hline
\end{tabular}

Whites

No. of respondents

Energy from saturated

$3144 \quad 3195$

$37.4 \pm 0.1 \quad 34.1 \pm 0.1$

2845

$38.1 \pm 0.1 \quad 34.8 \pm 0.1$

$381 \quad 2716$

1415

fat $(\%)$

Cholesterol (mg)

$426 \pm 6-334 \pm 4-272 \pm 4$

$14.7 \pm 0.1$

$13.7 \pm 0.04 \quad 12.2 \pm 0.1$

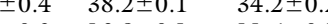

Fruits and vegetables

$\begin{array}{lll}426 \pm 6 & 334 \pm 4 & 272 \pm 4 \\ 4.3 \pm 0.04 & 4.5 \pm 0.03 & 4.3 \pm 0.03\end{array}$

$462 \pm 6 \quad 347 \pm 3 \quad 276 \pm 4$

$14.4+0.2$

(no. of servings)

Grains and legumes

(no. of servings)

Protein (\% of RDA)

Sodium (mg)

Calcium (\% of RDA)

$4.6 \pm 0.06 \quad 4.3 \pm 0.04 \quad 4.5 \pm 0.04$

$4.5 \pm 0.03$

$4.6 \pm 0.02 \quad 4.5 \pm 0.03$

$452 \pm 14 \quad 362 \pm 5$

Blacks

No. of respondents

Energy from fat (\%)

Energy from saturated

fat $(\%)$

Cholesterol (mg)

Fruits and vegetables (no. of servings)

Grains and legumes (no. of servings)

Protein (\% of RDA)

Sodium (mg)

$\begin{array}{ccc}147 \pm 2 & 130 \pm 1 & 125 \pm 1 \\ 3519 \pm 42 & 3015 \pm 28 & 3137 \pm 30 \\ 82 \pm 1 & 74 \pm 1 & 80 \pm 1\end{array}$

$4.1 \pm 0.05$

$4.2 \pm 0.02 \quad 4.7 \pm 0.04$

$4.7 \pm 0.09 \quad 4.9 \pm 0.03$

$261 \pm 5$

$166 \pm 2 \quad 145 \pm 0.7 \quad 139 \pm 1$

$3.7 \pm 0.11 \quad 3.9 \pm 0.04$

$4.8 \pm 0.06$

Calcium (\% of RDA)

$\begin{array}{ccc}504 & 1065 & 948 \\ 37.2 \pm 0.4 & 36.7 \pm 0 & 34.9 \pm 0.3 \\ 12.8 \pm 0.2 & 12.5 \pm 0.1 & 11.7 \pm 0.1 \\ 441 \pm 12 & 392 \pm 8 & 305 \pm 8 \\ 4.2 \pm 0.12 & 4.5 \pm 0.08 & 4.1 \pm 0.07 \\ & & \\ 5.5 \pm 0.14 & 4.7 \pm 0.08 & 4.5 \pm 0.07 \\ & & \\ 153 \pm 4 & 142 \pm 2 & 132 \pm 2 \\ 3643 \pm 84 & 3136 \pm 52 & 3086 \pm 60 \\ 73 \pm 2 & 62 \pm 1 & 60 \pm 1\end{array}$

$86 \pm 1$

$3249 \pm 18 \quad 3467 \pm 30$

$170 \pm 4 \quad 149 \pm 1$

$4.7 \pm 0.06$

$\begin{array}{ccc}179 & 763 & 328 \\ 38.9 \pm 0.7 & 37.3 \pm 0.3 & 34.7 \pm 0.5 \\ 13.9 \pm 0.3 & 12.7 \pm 0.1 & 12.1 \pm 0.2 \\ 502 \pm 25 & 399 \pm 10 & 311 \pm 15 \\ 4.5 \pm 0.16 & 4.7 \pm 0.08 & 5.4 \pm 0.16 \\ & & \\ 4.5 \pm 0.29 & 4.6 \pm 0.09 & 4.5 \pm 0.14 \\ & & \\ 179 \pm 7 & 144 \pm 2 & 142 \pm 4 \\ 3630 \pm 152 & 3110 \pm 55 & 3470 \pm 111 \\ 73 \pm 3 & 63 \pm 2 & 77 \pm 3\end{array}$

$601+94$

$\pm 1 \quad 138 \pm 2$

$\begin{array}{ccc}86 \pm 3 & 88 \pm 1 & 93 \pm 2\end{array}$

*The results were weighted to permit inferences applicable to the total noninstitutionalized U.S. population. Plus-minus values are means \pm SE.

†The sample was too small to present meaningful results. 
1989-1991, the respective percentages were 4.4 , 4.1, and 6.6.

Examination of the components of the Diet Quality Index reveals that by 1989-1991 the proportion of energy derived from fat dropped from nearly 40 percent in some groups to less than 35 percent for both races in all socioeconomic groups (Table 3 ). Blacks reported a marginally lower percentage of energy derived from saturated fat than whites in all periods, and by 1989-1991 the mean among blacks of high socioeconomic status approached the Diet Quality Index's target of 10 percent. The consumption of dietary cholesterol declined in all groups over time. The consumption of fruits and vegetables varied little over time, except that blacks of medium and high socioeconomic status increased their mean number of servings of these foods by one, to approach or meet the recommended five servings a day. In 1965, the consumption of grains and legumes was near the recommended level of six or more servings daily among blacks of low socioeconomic status. However, the mean number of servings in this group declined over time, from 5.5 in
1965 to 4.5 in 1989-1991. The consumption of grains and legumes, however, increased over time among whites of medium and high socioeconomic status, from, for example, 3.7 servings a day for whites of high socioeconomic status in 1965 to 4.7 in 1989-1991. Excessive consumption of protein and sodium declined over time; declines in the intake of protein were greatest among blacks of medium socioeconomic status and whites of high socioeconomic status, and declines in sodium consumption were greatest among blacks of low socioeconomic status. The differences in calcium intake related to race widened over time, with whites consuming more than blacks and groups of higher socioeconomic status consuming more than those of lower socioeconomic status.

To illustrate changes in consumption between 1965 and 1989-1991, the changes in the mean intake of foods from selected food groups by whites and blacks of low socioeconomic status and whites of high socioeconomic status are shown in Table 4. Blacks of high socioeconomic status are excluded because of the small sample in 1965. In 1989-1991,

\begin{tabular}{|c|c|c|c|c|c|c|}
\hline \multirow[t]{3}{*}{ FoOd Group } & \multicolumn{4}{|c|}{ Low Socioeconomic Status } & \multirow{2}{*}{\multicolumn{2}{|c|}{$\begin{array}{c}\text { High Socioeconomic Status } \\
\text { Whites }\end{array}$}} \\
\hline & \multicolumn{2}{|c|}{ WHITES } & \multicolumn{2}{|c|}{ BLACKS } & & \\
\hline & g & $\%$ change & g & $\%$ change & $\mathrm{g}$ & $\%$ change \\
\hline Low-fat milk & 120.3 & +607 & 44.8 & +92 & 163.4 & +256 \\
\hline High-fat milk & 0.3 & -92 & 1.3 & -66 & 0.17 & -99 \\
\hline Low-fat cheese & 3.9 & -38 & 0.77 & -61 & 4.1 & -65 \\
\hline High-fat cheese & 8.3 & +130 & 5.2 & +271 & 12.2 & +72 \\
\hline Butter and margarine & 5.8 & -55 & 4.4 & -56 & 6.1 & -50 \\
\hline Egg items & 22.4 & -45 & 32.4 & -24 & 16.8 & -52 \\
\hline Low-fat red meat & 44.7 & -13 & 42.3 & -6 & 41.4 & -47 \\
\hline Low-fat poultry & 24.4 & +77 & 19.5 & -26 & 36.3 & +157 \\
\hline Low-fat lunch meats & 4.9 & +965 & 4.5 & +350 & 5.0 & +1512 \\
\hline Low-fat fish & 9.0 & +52 & 5.1 & +8 & 21.4 & +21 \\
\hline High-fat red meat & 7.2 & -71 & 4.2 & -89 & 3.2 & -89 \\
\hline Bacon & 2.3 & -63 & 4.5 & -54 & 1.4 & -76 \\
\hline Low-fiber, low-fat bread & 27.3 & -52 & 32.2 & -42 & 12.3 & -69 \\
\hline High-fiber, low-fat bread & 18.1 & +135 & 10.0 & +212 & 28.6 & +135 \\
\hline Pasta, rice, cooked cereals & 56.8 & +66 & 94.3 & +8 & 52.9 & +224 \\
\hline High-fat grain-based mixes & 38.4 & +331 & 26.7 & +187 & 60.7 & +483 \\
\hline High-fiber ready-to-eat cereals & 6.0 & +150 & 2.7 & +1476 & 12.7 & +225 \\
\hline Citrus fruits & 45.1 & +18 & 49.9 & +53 & 82.1 & -18 \\
\hline Other fruits & 51.8 & -4 & 29.5 & -24 & 71.5 & -25 \\
\hline Dark-green and orange vegetables & s 17.5 & +21 & 26.5 & +3 & 24.6 & +44 \\
\hline Other vegetables & 64.2 & -9 & 32.2 & -26 & 89.3 & -21 \\
\hline Soups & 47.5 & +53 & 31.6 & +259 & 38.7 & +21 \\
\hline Soy products and legumes & 29.3 & 0 & 22.8 & -24 & 19.5 & +156 \\
\hline
\end{tabular}

${ }^{*}$ Data are from the 1965 Nationwide Food Consumption Survey and the 1989-1991 Continuing Survey of Food Intake by Individuals. The food groups shown have been selected from those we derived for this study. Amounts are given in grams per capita per day. Blacks of high socioeconomic status are not listed because of the small number of such respondents in the 1965 survey. 
whites of high socioeconomic status consumed lowfat foods more frequently than the other surveyed groups, reduced their intake of some high-fat foods, and increased their intake of high-fiber foods and nutrient-rich vegetables. Whites of low socioeconomic status increased their intake of low-fat foods over time, but the reductions in their intake of highfat foods were smaller than those of whites of high socioeconomic status. Whites of low socioeconomic status also had smaller increases in their consumption of high-fiber foods and nutrient-rich dark-green and orange vegetables than whites of high socioeconomic status.

In 1989-1991 as compared with 1965, blacks of low socioeconomic status consumed low-fat foods more frequently and reduced their intake of some high-fat foods such as high-fat milk, red meat, and bacon, but they had a greater increase in the consumption of high-fat cheese than the other groups. However, the number of grams of high-fat cheese consumed per capita by blacks of low socioeconomic status was still less than in the other groups. Blacks of low socioeconomic status also markedly increased their consumption of ready-to-eat high-fiber cereals and citrus fruits. They also decreased their consumption of vegetables other than dark-green and orange vegetables.

\section{DISCUSSION}

In general, the dietary patterns we examined with the Diet Quality Index suggest two main trends. First, the differences among racial and socioeconomic groups have narrowed over time. The overall improvement in mean Diet Quality Index scores over time reflects changing consumption patterns and increasing acceptance of dietary recommendations. The fat-related components of the index (consumption of cholesterol and of total and saturated fat) and protein intake follow this pattern; however, the mean number of servings of fruits and vegetables and the consumption of grains either have remained constant or have decreased in some groups, such as whites and blacks of low socioeconomic status. Changes related to food groups are more complex to interpret but generally show that whites of high socioeconomic status reduced their consumption of items in high-fat food groups and conformed to other dietary guidelines to a greater extent than did either whites or blacks of medium and low socioeconomic status.

Second, improvements in diet were more likely to occur in the groups of high socioeconomic status. With so few high-income blacks surveyed in 1965, we cannot describe trends in this group as clearly as we can in other groups, but our results suggest that this subgroup is more similar to whites of high so- cioeconomic status than to blacks of low socioeconomic status. In summary, although in 1965 there were large differences in dietary quality, with whites of high socioeconomic status eating the worst diets, as measured by the Dietary Quality Index, and blacks of low socioeconomic status the best, by 19891991, the diets of all groups were relatively similar.

Supported in part by a grant from the Kellogg Corporation.

We are indebted to Dr. Victor Fulgoni, Dr. Leila Saldanba, and Dr. Janet Tietyen of Kellogg, to Phil Bardsley and Kelly Gallagher for programming support, to Terri Carson for work in developing the food-group measures, to Lynn Igoe for editorial assistance, and to Frances Dancy for administrative support.

\section{REFERENCES}

1. Johnson CL, Rifkind BM, Sempos CT, et al. Declining serum total cholesterol levels among US adults: the National Health and Nutrition Examination Surveys. JAMA 1993;269:3002-8.

2. Keil JE, Sutherland SE, Knapp RG, Lackland DT, Gazes PC, Tyroler HA. Mortality rates and risk factors for coronary disease in black as compared with white men and women. N Engl J Med 1993;329:73-8.

3. Kuczmarski RJ. Prevalence of overweight and weight gain in the United States. Am J Clin Nutr 1992;55:Suppl:495S-502S

4. Kumanyika SK. Special issues regarding obesity in minority populations. Ann Intern Med 1993;119:650-4.

5. Block G, Rosenberger WF, Patterson BH. Calories, fat and cholesterol: intake patterns in the US population by race, sex and age. Am J Public Health $1988 ; 78: 1150-5$

6. Patterson BH, Block G, Rosenberger WF, Pee D, Kahle LL. Fruit and vegetables in the American diet: data from the NHANES II survey. Am J Public Health 1990;80:1443-9.

7. Lutz SM, Smallwood DM, Blaylock JR, Hama MY. Changes in food consumption and expenditures in low-income American households during the 1980's. Statistical bulletin. No. 870. Washington, D.C.: Department of Agriculture, 1993

8. Popkin BM, Haines PS, Reidy KC. Food consumption trends of US women: patterns and determinants between 1977 and 1985. Am J Clin Nutr 1989;49:1307-19.

9. Popkin BM, Guilkey DK, Haines PS. Food consumption changes of adult women between 1977 and 1985. Am J Agric Econ 1989;71:949. 59.

10. Popkin BM, Haines PS, Patterson RE. Dietary changes among older Americans, 1977-1987. Am J Clin Nutr 1992;55:823-30.

11. Tippett KS, Mickle SJ, Goldman JD, et al. Food and nutrient intakes by individuals in the United States, 1 day, 1989-91: continuing survey of food intake by individuals, 1989-91. Washington, D.C.: Department of Agriculture, 1995. (Nationwide Food Consumption Survey report no. 912.)

12. Peterkin BB, Rizek RL, Tippett KS. Nationwide food consumption survey, 1987. Nutr Today 1988;23(1):18-24.

13. Rizek RL. The 1977-78 nationwide food consumption survey. Fam Econ Rev 1978;4:3.

14. Food and nutrient intake of individuals in the United States. Spring 1965. Washington, D.C.: Agricultural Research Service, 1972.

15. Guenther PM, Perloff BP. Effects of procedural differences between 1977 and 1987 in the Nationwide Food Consumption Survey on estimates of food and nutrient intakes: results of the USDA 1988 Bridging Study. Washington, D.C.: Government Printing Office, 1990. (Nationwide Food Consumption Survey report no. 87-M-1.)

16. Guenther PM, Perloff BB, Vizioli TL Jr. Separating fact from artifact in changes in nutrient intake over time. J Am Diet Assoc 1994;94:270-5. 17. National Research Council, Committee on Diet and Health. Diet and health: implications for reducing chronic disease risk. Washington, D.C.: National Academy Press, 1989.

18. Patterson RE, Haines PS, Popkin BM. Diet quality index: capturing a multidimensional behavior. J Am Diet Assoc 1994;94:57-64

19. Idem. Health lifestyle patterns of U.S. adults. Prev Med 1994;23:453 60 . 